\title{
ORIGINAL ARTICLE Severe congenital anomalies of the kidney and urinary tract: epidemiology can inform ethical decision-making
}

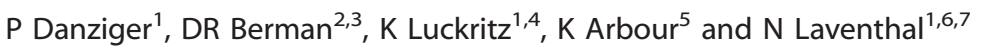

\begin{abstract}
OBJECTIVE: Decision-making for pregnancies complicated by severe congenital anomalies of the kidneys and urinary tract (CAKUT) are ethically challenging, partly because the outcomes are not well studied.

STUDY DESIGN: Retrospective cohort study of severe cases of CAKUT over 14 years.

RESULTS: Seventy-one of the 108 cases could be completely analyzed. Forty-six percent $(n=33)$ infants were live-born; one-third $(n=11)$ survived to 12 months. Twice as many non-surviving infants received a trial of therapy vs comfort care only. Two-thirds of non-survivors who received a trial of therapy died within the first $9 \mathrm{~h}$ of life. Live-born infants faced morbidities such as pneumothorax and neonatal dialysis.

CONCLUSIONS: Over half of pregnancies complicated by severe CAKUT ended in termination or stillbirth, but one-third of live-born infants survived to 12 months and the majority of non-survivors died within hours. This may allay concerns about prolonged and futile intensive care for parents considering a trial of therapy.
\end{abstract}

Journal of Perinatology (2016) 36, 954-959; doi:10.1038/jp.2016.107; published online 28 July 2016

\section{INTRODUCTION}

Congenital anomalies of the kidneys and urinary tract (CAKUT) are among the most common prenatally diagnosed structural abnormalities and represent a major cause of end-stage renal disease in children. ${ }^{1-8}$ Cases vary in severity from transient selflimited prenatal hydronephrosis to bilateral renal agenesis with associated pulmonary hypoplasia. ${ }^{4,9-11}$ Fetal and neonatal outcomes are also variable, ranging from intrauterine fetal demise to pregnancy termination to long-term survival. After birth, live-born infants may be treated with palliative or aggressive care. Advances in obstetric interventions, neonatal intensive care and pediatric nephrology have led to longer-term survival for some infants, ${ }^{12}$ but prognostic uncertainty and ongoing debate regarding the utilization of certain therapeutic options and the quality of life for survivors makes perinatal decision-making in these situations challenging for both families and clinicians.

Numerous studies have examined perinatal and long-term outcomes of fetuses with CAKUT, ${ }^{3,4,13-25}$ but current literature has limitations. Only a small subset, primarily based in Europe, focus on the most severely affected fetuses, such as those with oligohydramnios of renal origin or severe bilateral disease. $3,13,16,18,19,21,26$ Many have small sample sizes and include subjects with extrarenal anomalies or aneuploidy. Furthermore, many of the studies have the potential for significant selection bias and confounding based on their design and case identification. Few identify cases from initial prenatal diagnosis and follow them through infancy or beyond.

Ethical analyses of outcomes and decision-making for this patient population are not uniform. Some ${ }^{4,12,19}$ have identified justification for cautious optimism, identifying non-trivial numbers of both short- and long-term survivors, and recognizing the potential challenges to these infants and their caregivers. Others have offered a more pessimistic view, citing the high mortality rate and prognostic difficulties that remain for these pregnancies. $^{3,16}$

Given the limitations in the existing data regarding epidemiology and outcomes, and the prognostic and ethical challenges in caring for these patients, our objective was to provide data and analysis from a major tertiary referral institution in the United States in order to improve perinatal counseling and decision-making for families facing such diagnoses.

\section{MATERIALS AND METHODS}

Patients and methods

We performed a retrospective cohort study of all cases of prenatally identified severe, isolated CAKUT at our institution over a 14-year period. Cases were identified via an institutional obstetrical ultrasound database maintained in the Fetal Diagnostic Center at the University of Michigan C.S. Mott Children's Hospital and Von Voigtlander Women's Hospital. All pregnancies with a prenatal diagnosis of severe renal and/or urinary tract anomalies based on ultrasound findings between 2000 and 2014 were identified. Severe cases were defined as those with bilaterally affected kidneys with documented concern for significant renal insufficiency. Exclusion criteria included non-singleton pregnancy, aneuploidy, bladder/cloacal exstrophy and congenital anomalies of other organ systems.

Maternal and infant medical records were reviewed to obtain further information on the pregnancy and clinical course. Cases were followed from initial presentation to our center until fetal demise, infant death or through 12 months of age for survivors. 'Neonatal period' was defined as 0 to 28 days of life and 'postneonatal period' as 28 to 364 days of life. ${ }^{27}$

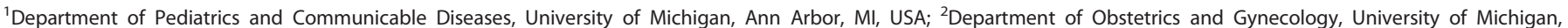

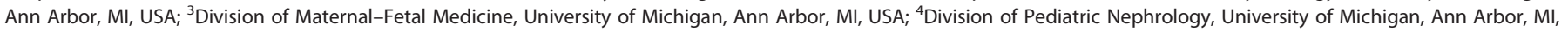

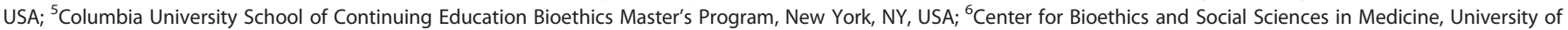

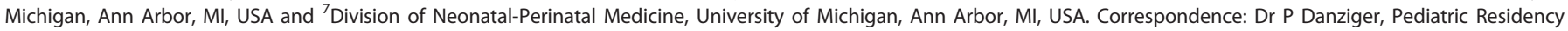
Program, University of Michigan Health System, 1500 E. Medical Center Drive, Medical Professional Building, Room D3227, SPC 5718, Ann Arbor, MI 48109-5718, USA. 
In order to maximize comparability with existing literature and to differentiate between conditions with distinct embryological, molecular and/or genetic etiologies and clinical courses, we categorized fetuses in the following manner: polycystic kidney disease, dysplastic kidneys (including multicystic dysplastic kidneys and renal agenesis), lower urinary tract obstruction, and unknown. Patients were assigned to the 'unknown' category when the prenatal differential encompassed more than one diagnostic category or was unclear.

Amniotic fluid volume was assessed quantitatively via maximum vertical pocket and qualitatively by the perinatologist performing the ultrasound. Oligohydramnios was defined as maximum vertical pocket $<2 \mathrm{~cm}$; anhydramnios was identified if there was no measureable pocket of fluid. Gestational age (GA) was determined using 'assigned $\mathrm{GA}^{\prime}$ ' documented in ultrasound reports based on a combination of definite last menstrual period, ultrasound and clinical judgment.

For live-born infants, those who did not receive any treatments aimed at prolonging life were classified as receiving comfort care only. Infants who initially received resuscitative measures, including but not limited to mechanical ventilation, chest compressions, umbilical line placement and pressor support but for whom life-sustaining measures were stopped and goals of care were directed to comfort, were classified as receiving a trial of therapy with subsequent redirection to comfort care. Infants who received full resuscitative and/or life-prolonging care when applicable, with no documentation of redirection of goals of care to comfort or palliation, were classified as receiving aggressive care only.

\section{Ethics}

This study was approved by the Institutional Review Boards of the University of Michigan Medical School (HUM00031524).

\section{Statistical analysis}

Study data were collected and managed using REDCap (Research Electronic Data Capture) tools hosted at the University of Michigan. ${ }^{28}$ REDCap is a secure, web-based application designed to support data capture for research studies. Additional data were compiled in Microsoft Excel (Redmond, Washington, USA), and Stata was used to perform statistical analyses (StataCorp. 2011. Stata Statistical Software: Release 12, StataCorp, College Station, TX, USA). Data are presented as mean with s.d. for normally distributed variables; variables with a non-normal distribution are presented as a median with a five-number summary. Comparative analyses performed included Fisher's exact test and simple logistic regression.

\section{RESULTS}

We identified 1035 cases with fetal renal and/or urinary tract anomalies based on prenatal ultrasound. Of these, 108 cases were eligible, with full outcome data available for 71 cases, which comprise the final population included in the analysis (Figure 1). Characteristics of the 37 eligible patients for whom no further records were available at our institution are available in Supplementary Appendix S1.

Prenatal characteristics

Table 1 presents the baseline characteristics of the women and fetuses in our cohort, the majority of whom were referred to our center after the identification of an anomaly (82\%). The mean $\mathrm{GA}$ at the time of the first ultrasound identifying the anomaly, or the first ultrasound performed at our institution, was 21 2/7 weeks (s.d. $=30$ days, range 11 to $312 / 7$ weeks). A range of diagnoses were represented; urinary tract obstruction was the most common (48\%). Forty-five percent of pregnancies were terminated (median 21 weeks GA, range $163 / 7$ to $233 / 7$ ) (Figure 1); these women had the lowest mean GA at the time of diagnosis or referral (mean 19 $3 / 7$ weeks, s.d. $=17$ days, range $121 / 7$ to $232 / 7$ ). In contrast, pregnancies that resulted in infants who survived to 12 months of age had the highest mean GA at presentation (24 4/7 weeks, s.d. $=40$ days), range $140 / 7$ to $312 / 7$ ). Eight and a half percent of pregnancies resulted in intrauterine fetal demise (median GA 31 2/7 weeks, range $290 / 7$ to 38 4/7 weeks). There were 33 live births

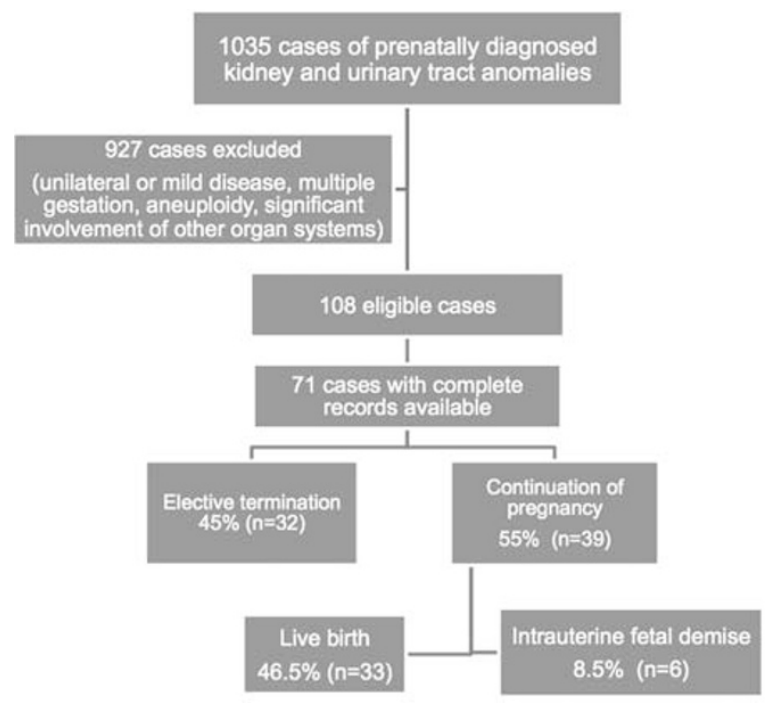

Figure 1. Recruitment and pregnancy outcomes.

(median GA at delivery $343 / 7$ weeks, range $260 / 7$ to 39 2/7 weeks) (Figure 1).

We considered the presence of oligohydramnios or anhydramnios or documentation of poor pulmonary prognosis to be risk factors for poor outcomes such as infant death and to be more likely to result in pregnancy termination. Although there did appear to be disproportionately more terminations and postnatal infant deaths among women who had these risk factors, these differences were not statistically significant (Table 1). Sixty-eight percent of infants who died were assigned a poor pulmonary prognosis prenatally, compared with $27 \%$ of survivors; this result approached statistical significance $(P=0.06$; Table 1$)$.

Delivery and live-birth outcomes

Table 2 presents delivery and resuscitation characteristics for the cohort of live-born infants $(n=33)$. Forty-nine percent of deliveries were via cesarean delivery $(n=16)$. Of these, $44 \%(n=7)$ were repeat cesarean deliveries; the remainder $(n=9)$ were primary cesarean delivery for fetal or maternal indications. Though survivors had a higher median GA at birth (35 1/7 vs 34 weeks), there was no statistically significant difference in mean GA, mean birth weight or rate of primary cesarean delivery between survivors and non-survivors (Table 2 ).

Figure 2 displays the outcomes of the 33 live-born infants in the cohort. About one-third of these infants survived to 12 months of age. Of those who died in infancy, the largest group received a 'trial of therapy' with subsequent redirection of care $(55 \%, n=12)$. Among the infants who received a 'trial of therapy', 75\% $(n=9)$ died in the neonatal period, and $67 \%$ of these infants $(n=6)$ died within the first $9 \mathrm{~h}$ of life (not shown). Length of survival for all infants who died in the neonatal period ranged from approximately $10 \mathrm{~min}$ of life to 20 days. Six (27\%) of these non-survivors received comfort care only at birth; all of these infants died within the first $3 \mathrm{~h}$ of life. In one case, comfort care only was planned, but the infant had a better clinical appearance than expected at birth, thus full resuscitation was initiated. This infant survived through 1 year of age. There were four non-survivors for whom the postnatal care plan was unclear from the medical documentation.

Fifty-two percent of live-born infants ( $n=16$, of 31 for whom this data was clearly documented in the medical record) had spontaneous respirations at birth; $61 \%(n=19)$ were endotracheally intubated during initial resuscitation (Table 2). Survivors were more likely than non-survivors to have spontaneous respirations at 
Table 1. Prenatal characteristics

\begin{tabular}{|c|c|c|c|c|c|c|}
\hline & $\begin{array}{l}\text { Survivors } \\
(\mathrm{n}=11)\end{array}$ & $\begin{array}{c}\text { Neonatal and postneonatal } \\
\text { deaths }(n=22)\end{array}$ & $\begin{array}{l}\text { Termination } \\
\quad(\mathrm{n}=32)\end{array}$ & IUFD $(\mathrm{n}=6)$ & Total $(\mathrm{n}=71)$ & $\mathrm{P}$ \\
\hline \multicolumn{7}{|c|}{ Gestational age at identification of anomaly or referral (weeks) } \\
\hline Range & 14 0/7-31 2/7 & $110 / 7-304 / 7$ & $121 / 7-232 / 7$ & $162 / 7-221 / 7$ & $110 / 7-312 / 7$ & \\
\hline Mean (s.d.) & $244 / 7$ weeks & $225 / 7$ weeks & $193 / 7$ weeks & $195 / 7$ weeks & $212 / 7$ weeks & \\
\hline First trimester (0-13 6/7 weeks) & $0(0 \%)$ & $1(5 \%)$ & $1(3 \%)$ & $0(0 \%)$ & $2(3 \%)$ & \\
\hline Second trimester (14 0/7-27 6/7 weeks) & $6(55 \%)$ & $18(82 \%)$ & $31(97 \%)$ & $6(100 \%)$ & $59(83 \%)$ & \\
\hline Third trimester ( $280 / 7$ on) & $5(45 \%)$ & $3(14 \%)$ & $0(0 \%)$ & $0(0 \%)$ & $10(14 \%)$ & \\
\hline Referred from outside institution & $9(82 \%)$ & $17(77 \%)$ & $29(91 \%)$ & $3(50 \%)$ & $58(82 \%)$ & \\
\hline Polycystic & $1(9 \%)$ & $6(27 \%)$ & $2(6 \%)$ & $0(0 \%)$ & $11(16 \%)$ & \\
\hline Dysplastic & $1(9 \%)$ & $4(18 \%)$ & $11(34 \%)$ & $1(17 \%)$ & $17(24 \%)$ & \\
\hline LUTO & $6(55 \%)$ & $9(41 \%)$ & $16(50 \%)$ & $3(50 \%)$ & $34(48 \%)$ & \\
\hline Unknown & $3(27 \%)$ & $2(9 \%)$ & $3(9 \%)$ & $2(33 \%)$ & $9(13 \%)$ & \\
\hline \multicolumn{7}{|c|}{ Maternal age at pregnancy outcome (termination, IUFD or live birth) (years) } \\
\hline Range & $19-39$ & $17-38$ & $15-42$ & $20-40$ & $15-42$ & \\
\hline Mean (s.d.) & $26(7)$ & $26(6)$ & $28(6)$ & $32.5(7)$ & $28(6)$ & $\begin{array}{l}\text { Terminated vs } \\
\text { non-terminated } 0.64\end{array}$ \\
\hline Anhydramnios at presentation to our institution & $2(18 \%)$ & $8(36 \%)$ & $15(47 \%)$ & $2(33 \%)$ & $27(38 \%)$ & $\begin{array}{l}\text { Survivors vs non-survivors } 0.43 \\
\text { Terminated vs } \\
\text { non-terminated } 0.22\end{array}$ \\
\hline Poor pulmonary prognosis documented prenatally & $3(27 \%)$ & $15(68 \%)$ & $21(66 \%)$ & $4(67 \%)$ & $43(61 \%)$ & $\begin{array}{l}\text { Survivors vs non-survivors } 0.06 \\
\text { Terminated vs } \\
\text { non-terminated } 0.5\end{array}$ \\
\hline
\end{tabular}


birth ( $82 \%, n=9$ vs $35 \%, n=7, P=0.02)$, and survivors had significantly higher 1-min Apgar scores than non-survivors (median 5 vs 3 for survivors and non-survivors, $P=0.02$ ) (Table 2). Seventy-five percent of the 24 infants who received life-prolonging care were intubated during initial resuscitation ( $n=18$; not shown). For nearly all of the infants who received a 'trial of therapy' with subsequent redirection to palliative care only, the 'trial of therapy' included intubation ( $92 \%, n=11$; Table 2). One-quarter of the 33 live-born infants $(24 \%, n=8)$ were diagnosed with unilateral or bilateral pneumothorax shortly following delivery, for which $88 \%$ received intervention (Table 3 ). Nearly one-third $(29 \%, n=9)$ of the 33 live-born infants were placed on high-frequency ventilators during their hospital course (Table 3 ). The cause of death was determined to be primarily due to respiratory causes in $68 \%$ of non-survivors and multifactorial, including a respiratory

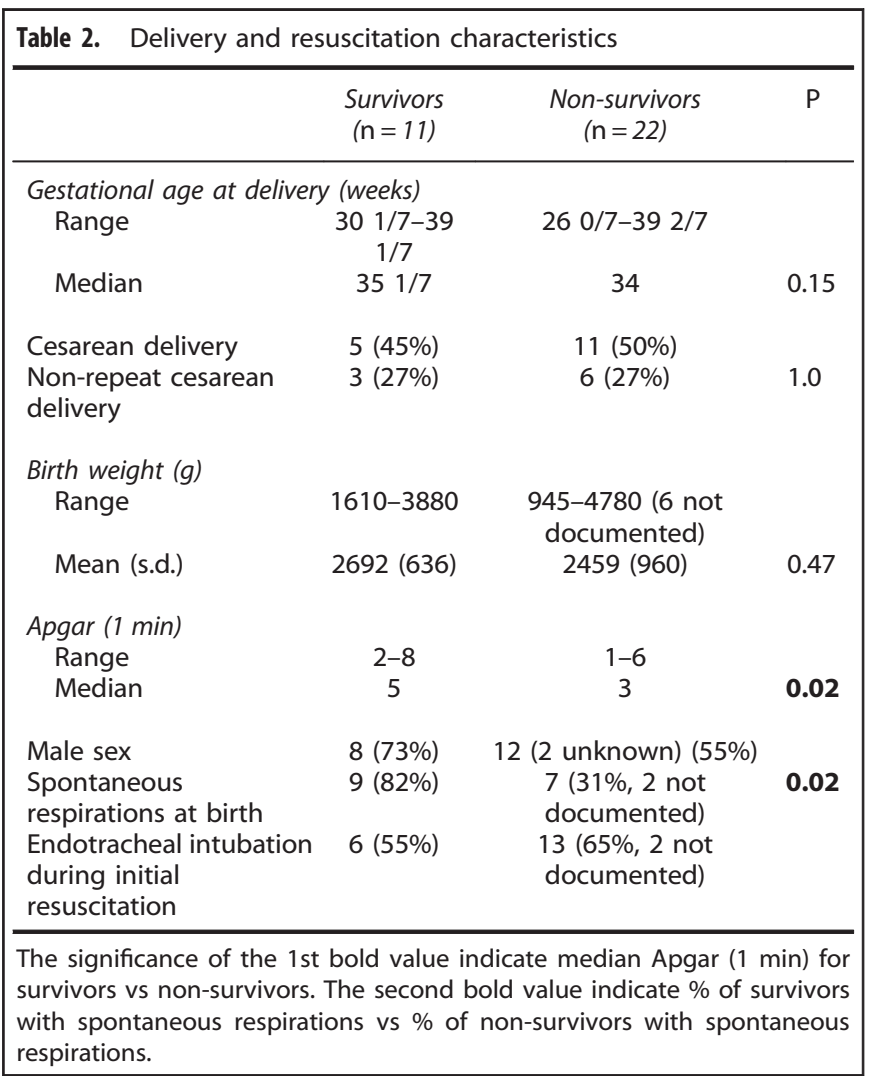

component, in the additional $18 \%$ of cases for which clear information on cause of death is available (Table 3 ).

Dialysis was initiated in 10 of the 33 live-born infants (30\%) (Table 3), and in 10 of the 19 (53\%) of all live-born infants who survived at least $24 \mathrm{~h}$ of life (data not shown). Age at initiation of dialysis ranged from 6 days to 2 months and 10 days. Fifty-five percent $(n=6)$ of the 11 infants who survived to 12 months of age required dialysis. Five of the six surviving infants who received dialysis remained on dialysis through 1 year of age, while the remaining infant received dialysis for 20 days until dialysis was no longer required.

Fifty percent $(n=4)$ of the 8 non-survivors who survived past $24 \mathrm{~h}$ of age received dialysis; all of these infants remained on dialysis until death. Dialysis appears not to have been provided to the remainder of non-surviving infants owing to futility. Eight of the 10 infants who received dialysis received peritoneal dialysis only; one received hemodialysis only owing to clinical instability and plan for future bilateral nephrectomies with placement of peritoneal dialysis catheter at that time. One infant received peritoneal dialysis initially and was switched emergently to hemodialysis when bowel resection was performed in the setting of necrotic bowel. The possibility of future renal transplantation was discussed and documented in five cases.

Seventy-three percent of the 11 infants who survived to 1 year of age $(n=8)$ had a gastrostomy tube placed by 1 year of age for nutritional support (Table 3). Twenty-one percent of the 33 live-born infants $(n=7)$ had documented abnormal neurological findings ranging from resolved grade I intraventricular hemorrhage to severe hypoxic-ischemic encephalopathy (Table 3). Twenty-seven percent of survivors $(n=3)$ had documented neurological abnormalities, including ischemic injury secondary to embolic strokes, and subdural hematoma with seizures and developmental delay. Ninety-one percent of survivors $(n=10)$ had medical complications in the first year of life, including chronic kidney disease, anemia, sepsis, urinary tract infection, hypertension and nutritional and metabolic complications of chronic kidney disease (Table 3).

\section{DISCUSSION}

Our study is one of the largest of its kind to date focusing on severe isolated CAKUT, following the full course from time of diagnosis or referral through the first year of life for survivors. It is one of the only cohorts based in the United States, which differs from the European countries in which the majority of comparable studies were performed with respect to cultural, religious and politico-legal aspects regarding pregnancy termination for fetal anomalies, attitudes toward palliative care and utilization of certain therapeutic interventions, such as neonatal dialysis.

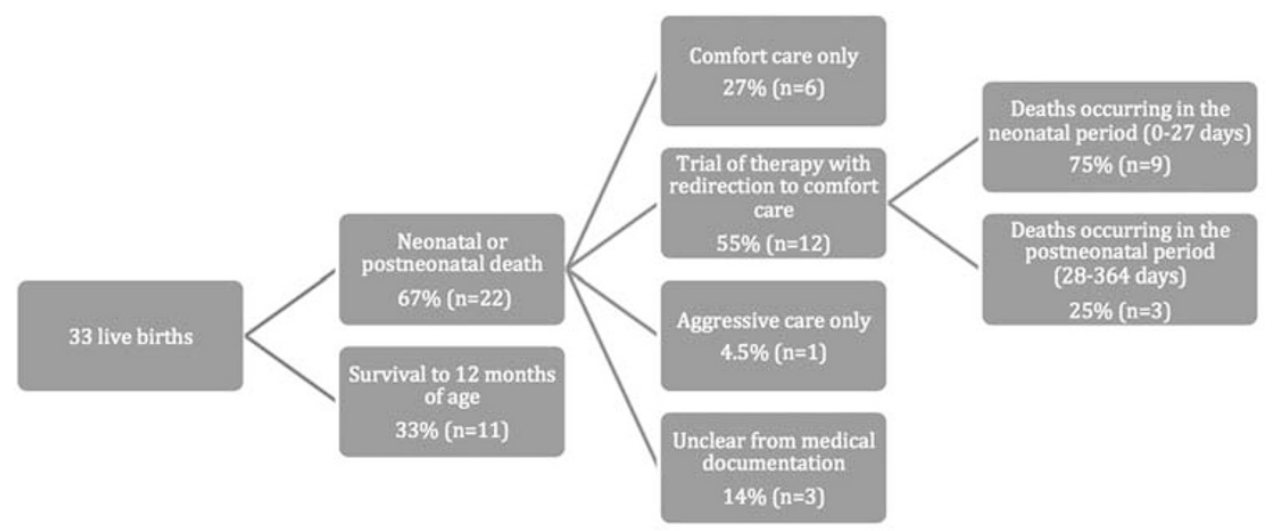

Figure 2. Outcomes for live-born infants. 
Table 3. Pulmonary, renal and other outcomes

\begin{tabular}{|c|c|c|c|}
\hline & Survivors $(\mathrm{n}=11)$ & Non-survivors $(\mathrm{n}=22)$ & Total $(\mathrm{n}=33)$ \\
\hline \multicolumn{4}{|l|}{$\begin{array}{l}\text { Highest level of ventilatory support during hospitalization ( } n=31 \text { with clear } \\
\text { records regarding ventilatory support) }\end{array}$} \\
\hline High-frequency ventilation (jet/oscillator) & $4(36 \%)$ & $5(25 \%)$ & $9(29 \%)$ \\
\hline Conventional mechanical ventilation & $3(27 \%)$ & $9(45 \%)$ & $12(39 \%)$ \\
\hline CPAP & $1(9 \%)$ & $0(0 \%)$ & $1(3 \%)$ \\
\hline Nasal cannula & $1(9 \%)$ & $0(0 \%)$ & $1(3 \%)$ \\
\hline None/blow-by & $2(18 \%)$ & $6(30 \%)$ & $8(26 \%)$ \\
\hline Pneumothorax (unilateral or bilateral) & $5(45 \%)$ & $3(14 \%)$ & $8(24 \%)$ \\
\hline Thoracostomy tube or needle decompression & $4(36 \%)$ & $3(14 \%)$ & $7(21 \%)$ \\
\hline Dialysis offered and not initiated & $0(0 \%)$ & $0(0 \%)$ & $0(0 \%)$ \\
\hline Dialysis initiated & $6(55 \%)$ & $4(18 \%)$ & $10(30 \%)$ \\
\hline Peritoneal dialysis & $6(55 \%)$ & $3(14 \%)$ & $9(90 \%)$ \\
\hline Hemodialysis & $0(0 \%)$ & $2(9 \%)$ & $2^{a}(20 \%)$ \\
\hline Age of initiation at dialysis (range) & $\begin{array}{l}16 \text { days }-2 \text { months } \\
10 \text { days }\end{array}$ & $6-10$ days & $\begin{array}{l}6 \text { days }-2 \text { months } \\
10 \text { days }\end{array}$ \\
\hline Length of time on dialysis & $20-343+$ days & $\begin{array}{l}4 \text { days }-3 \text { months } \\
7 \text { days }\end{array}$ & 4 days $-343+$ days \\
\hline Documented discussion of possible future renal transplantation & $5(45 \%)$ & $0(0 \%)$ & $5(15 \%)$ \\
\hline Gastrostomy tube prior to 1 year of age & $8(73 \%)$ & $0(0 \%)$ & $8(24 \%)$ \\
\hline Abnormal neurological findings documented & $3^{\mathrm{b}}(27 \%)$ & $4^{c}(18 \%)$ & $7(21 \%)$ \\
\hline \multicolumn{4}{|l|}{ Cause of death in non-survivors } \\
\hline Respiratory & NA & $15(68 \%)$ & NA \\
\hline Multifactorial & NA & $4(18 \%)$ & NA \\
\hline Unclear & NA & $3(14 \%)$ & NA \\
\hline
\end{tabular}

Abbreviations: CPAP, continuous positive airway pressure; NA, not applicable. ${ }^{a}$ Two received both peritoneal dialysis and hemodialysis. ${ }^{\mathrm{b}}$ Includes ischemic injury, subdural hematoma with seizure activity and subdural and subarachnoid hemorrhage. Includes grade I intraventricular hemorrhage that resolved, left germinal matrix hemorrhage and hypoxic-ischemic encephalopathy.

The termination rate in this cohort (45\%) was lower than in comparable European studies (55\% to $62 \%),{ }^{16,18,26,29}$ which may be due to cultural, religious and other differences between Europe and the United States. In a qualitative study of women who received a prenatal diagnosis of severe lower urinary tract obstruction, the authors note that while 'discourses around individual choice and decision making in these situations are usually presented as private moral dilemmas ... they take place within a social context where values, the meaning of disability, and quality of life are influential'. ${ }^{30}$ In our study, mothers who chose pregnancy termination were older in our cohort; however, we were unable to assess other demographic characteristics likely to be associated with perinatal decision-making such as religiosity and education level.

Our results highlight the use of amniotic fluid volume as an important but imperfect prognostic indicator. The majority of liveborn infants who presented with oligohydramnios or anhydramnios did not survive. The two infants who presented with anhydramnios and survived to 1 year of age had mothers who presented to our institution in the third trimester of pregnancy and likely had late-onset anhydramnios past the critical stages of pulmonary development.

Prenatal documentation of pulmonary prognosis ranged from absent to very detailed. Explicit prenatal diagnosis of 'lethal pulmonary hypoplasia' was made in some cases, though this term refers to pathological diagnosis that can be made only on the basis of tissue samples. Survivors were less likely to have a documented poor pulmonary prognosis compared with the other groups, suggesting that clinical assessment of prognosis remains helpful but imperfect, as one-quarter of infants who survived to 1 year of age were given a poor pulmonary prognosis prenatally; this included one infant whose condition was described prenatally as being expected to result in 'almost certain lethality' and for whom comfort care only was clearly planned, until a better-than- expected clinical appearance at birth led to full resuscitation. Our assessment of pulmonary prognosis in this study is a qualitative interpretation of medical documentation and likely depends on external factors such as provider differences in documentation and prognostic expertise, but these results highlight two important conclusions: first, that prognosis alone does not guide decision-making, as half of pregnancies assigned a poor prognosis were continued and half were terminated, and second, that prognosis did not uniformly predict outcome.

The majority of infants received either a trial of therapy with redirection to comfort care or full life-sustaining treatment as medically indicated. For families choosing pregnancy continuation, choosing a trial of therapy may be a meaningful decision that allows them to feel that they have not 'given up too soon' or that they have 'given the baby a chance.' Conversely, it may also reflect discomfort among families, providers or both with the idea of withholding potentially helpful therapies or with prognostic uncertainty.

In one of the few other studies to examine goals of care at birth in infants with CAKUT, $60 \%$ of infants in a Dutch cohort who died in the neonatal period received comfort care only, compared with $27 \%$ of non-survivors in our cohort, ${ }^{16}$ a discrepancy that may reflect cultural differences toward end-of-life care. However, of the non-survivors in our cohort who died after a trial of therapy, the majority died within the first $9 \mathrm{~h}$ of life, suggesting that the infants who do receive a trial of therapy generally do not receive prolonged or excessive course of treatment prior to death.

Our findings are relevant to ethical considerations surrounding renal dialysis initiated in the neonatal and infant periods. There is a wide range of opinions regarding whether renal replacement therapy is morally and ethically obligatory in infants, and these attitudes appear to vary by professional role (for example, physician vs nurse) and by patient age at initiation. ${ }^{7,12,31-33}$ There is continued debate regarding the role of non-medical 
considerations related to dialysis, such as the cost of care, and the burdens that families may experience in the setting of chronic dialysis. $^{31,33}$

This study has several limitations. Thirty-four percent of eligible cases, primarily patients who were referred from other institutions and resumed care there after a consultation at our center, did not have full outcome information available (Supplementary Appendix S1). Clinical course prior to referral was not available for some referred patients, preventing determination of important characteristics such as amniotic fluid trends in these patients. Some survivors did not receive follow-up care exclusively at our institution; complications and morbidities may thus be underestimated. Finally, our study encompasses multiple varieties of CAKUT that possess different epidemiological, genetic and molecular characteristics and are associated with different ranges of severity and prognosis, highlighting the need for highly individualized counseling for families in these scenarios. Despite these limitations, our results highlight the ways in which epidemiological studies can both illuminate and impact the ethics of perinatal decision-making in these medically and morally challenging cases.

\section{CONCLUSIONS}

Perinatal decision-making in cases of CAKUT remains complex and value-laden for families and providers. Prenatal prognosticating is helpful but imperfect. Families concerned that a trial of therapy may lead to prolonged, burdensome and potentially futile intensive care may be reassured that the majority of nonsurvivors died shortly after birth following redirection to comfort care; however, non-trivial rates of morbidity, mortality and complications suggest that postnatal comfort care remains an ethically permissible choice.

\section{CONFLICT OF INTEREST}

The authors declare no conflict of interest.

\section{ACKNOWLEDGEMENTS}

We thank Dr Marcie Treadwell (Division of Maternal and Fetal Medicine, Department of Obstetrics and Gynecology, University of Michigan), Jeannie Kreutzman, Michigan Institute for Clinical and Health Research grant support (CTSA: UL1TR000433) for REDCap use and Corey Powell at the University of Michigan Center for Statistical Consultation and Research.

\section{REFERENCES}

1 Carr MC, Kim SS. Prenatal management of urogenital disorders. Urol Clin North Am 2010; 37(2): 149-158.

2 Clayton DB, Brock JW 3rd. Prenatal ultrasonography: implications for pediatric urology. J Pediatr Urol 2011; 7(2): 118-125.

3 Hogan J, Dourthe ME, Blondiaux E, Jouannic JM, Garel C, Ulinski T. Renal outcome in children with antenatal diagnosis of severe CAKUT. Pediatr Nephrol 2012; 27(3): 497-502.

4 Kemper MJ, Mueller-Wiefel DE. Prognosis of antenatally diagnosed oligohydramnios of renal origin. Eur J Pediatr 2007; 166(5): 393-398.

5 Kerecuk L, Schreuder MF, Woolf AS. Renal tract malformations: perspectives for nephrologists. Nat Clin Pract Nephrol 2008; 4(6): 312-325.

6 Lissauer D, Morris RK, Kilby MD. Fetal lower urinary tract obstruction. Semin Fetal Neonatal Med 2007; 12(6): 464-470.

7 Rees L. Paediatrics: infant dialysis--what makes it special? Nat Rev Nephrol 2013; 9(1): 15-17.

8 Wiesel A, Queisser-Luft A, Clementi M, Bianca S, Stoll C. Prenatal detection of congenital renal malformations by fetal ultrasonographic examination: an analysis of 709,030 births in 12 European countries. Eur J Med Genet 2005; 48(2): 131-144.

9 Lee RS, Cendron M, Kinnamon DD, Nguyen HT. Antenatal hydronephrosis as a predictor of postnatal outcome: a meta-analysis. Pediatrics 2006; 118(2): 586-593.

10 Thomas DF. Prenatally diagnosed urinary tract abnormalities: long-term outcome. Semin Fetal Neonatal Med 2008; 13(3): 189-195.

11 Woodhouse CR, Neild GH, Yu RN, Bauer S. Adult care of children from pediatric urology. J Urol 2012; 187(4): 1164-1171.

12 Carey WA, Martz KL, Warady BA. Outcome of patients initiating chronic peritoneal dialysis during the first year of life. Pediatrics 2015; 136(3): e615-e622.

13 Carpenter MW, Corrado F, Sung J. Lethal fetal renal anomalies and obstetric outcome. Eur J Obstet Gynecol Reprod Biol 2000; 89(2): 149-152.

14 Damen-Elias HA, De Jong TP, Stigter RH, Visser GH, Stoutenbeek PH. Congenital renal tract anomalies: outcome and follow-up of 402 cases detected antenatally between 1986 and 2001. Ultrasound Obstet Gynecol 2005; 25(2): 134-143.

15 Gloor JM, Ogburn PL Jr, Breckle RJ, Morgenstern BZ, Milliner DS. Urinary tract anomalies detected by prenatal ultrasound examination at Mayo Clinic Rochester. Mayo Clinic Proc Mayo Clinic 1995; 70(6): 526-531.

16 Grijseels EW, van-Hornstra PT, Govaerts LC, Cohen-Overbeek TE, de Krijger RR, Smit BJ et al. Outcome of pregnancies complicated by oligohydramnios or anhydramnios of renal origin. Prenat Diagn 2011; 31(11): 1039-1045.

17 Hsieh MH, Lai J, Saigal CS, Urologic Diseases in America Project. Trends in prenatal sonography use and subsequent urologic diagnoses and abortions in the United States. J Pediatr Urol 2009; 5(6): 490-494.

18 Jouannic JM, Hyett JA, Pandya PP, Gulbis B, Rodeck $\mathrm{CH}$, Jauniaux E. Perinatal outcome in fetuses with megacystis in the first half of pregnancy. Prenat Diagn 2003; 23(4): 340-344.

19 Klaassen I, Neuhaus TJ, Mueller-Wiefel DE, Kemper MJ. Antenatal oligohydramnios of renal origin: long-term outcome. Nephrol Dial Transplant 2007; 22(2): 432-439.

20 Mallik M, Watson AR. Antenatally detected urinary tract abnormalities: more detection but less action. Pediatr Nephrol 2008; 23(6): 897-904.

21 Mehler K, Beck BB, Kaul I, Rahimi G, Hoppe B, Kribs A. Respiratory and general outcome in neonates with renal oligohydramnios--a single-centre experience. Nephrol Dial Transplant 2011; 26(11): 3514-3522.

22 Melo BF, Aguiar MB, Bouzada MC, Aguiar RL, Pereira AK, Paixao GM et al. Early risk factors for neonatal mortality in CAKUT: analysis of 524 affected newborns. Pediatr Nephrol 2012; 27(6): 965-972.

23 Morris RK, Kilby MD. Long-term renal and neurodevelopmental outcome in infants with LUTO, with and without fetal intervention. Early Hum Dev 2011; 87(9): 607-610.

24 Podevin G, Mandelbrot L, Vuillard E, Oury JF, Aigrain Y. Outcome of urological abnormalities prenatally diagnosed by ultrasound. Fetal Diagn Ther 1996; 11(3): 181-190.

25 Quirino IG, Diniz JS, Bouzada MC, Pereira AK, Lopes TJ, Paixao GM et al. Clinical course of 822 children with prenatally detected nephrouropathies. Clin J Am Soc Nephrol 2012; 7(3): 444-451.

26 Spaggiari E, Stirnemann JJ, Heidet L, Dreux S, Ville Y, Oury JF et al. Outcome following prenatal diagnosis of severe bilateral renal hypoplasia. Prenat Diagn 2013; 33(12): 1167-1172.

27 Barfield WD, Committee on Fetus and Newborn. Standard terminology for fetal, infant, and perinatal deaths. Pediatrics 2011; 128(1): 177-181.

28 Harris PA, Taylor R, Thielke R, Payne J, Gonzalez N, Conde JG. Research electronic data capture (REDCap)--a metadata-driven methodology and workflow process for providing translational research informatics support. J Biomed Inform 2009; 42(2): 377-381.

29 Ryckewaert-D'Halluin A, Le Bouar G, Odent S, Milon J, D'Herve D, Lucas J et al. Diagnosis of fetal urinary tract malformations: prenatal management and postnatal outcome. Prenat Diagn 2011; 31(11): 1013-1020.

30 Denny E, Quinlan-Jones E, Bibila S, Kilby M. The experience of pregnant women with a diagnosis of fetal lower urinary tract obstruction (LUTO). Midwifery 2013; 30(6): 636-642.

31 Lantos JD, Warady BA. The evolving ethics of infant dialysis. Pediatr Nephrol 2013; 28(10): 1943-1947.

32 Shooter M, Watson A. The ethics of withholding and withdrawing dialysis therapy in infants. Pediatr Nephrol 2000; 14(4): 347-351.

33 Teh JC, Frieling ML, Sienna JL, Geary DF. Attitudes of caregivers to management of end-stage renal disease in infants. Peritoneal Dial Int 2011; 31(4): 459-465.

Supplementary Information accompanies the paper on the Journal of Perinatology website (http://www.nature.com/jp) 